\title{
Wake up call
}

\author{
Om Prakash Yadava ${ }^{1}$
}

Received: 7 July 2017 / Accepted: 12 July 2017 / Published online: 28 July 2017

(C) Indian Association of Cardiovascular-Thoracic Surgeons 2017

Medical profession in general, and cardiothoracic and vascular surgery (CTVS) in specific, seems to have lost its sheen lately. Not bemoaning the various factors responsible for the same, including the one we ourselves are responsible for in no small measure - the 'Holier than Thou' image of a cardiac surgeon, and which has contributed no ends to the current state of affairs. It was inculcated in us that one had to be a superman to be a cardiac surgeon and train for long hours and that we had to be a breed different from the mundane to qualify to make a cardiac surgeon. Today I realize, nothing was further from truth.

Cardiac surgery after all is just another branch of medicine and the same parameters applicable for training to other specialities could well be applied to CTVS including the resident working hours. The Accreditation Council for Graduate Medical Education (ACGME) recently issued revised common programme requirements for residents that have gone into effect from July 2017 maintaining an $80 \mathrm{~h} /$ week caps on residents work, with a maximum limit of a single shift of $24 \mathrm{~h}$. To me, even this is rather draconian — compare it to $8 \mathrm{~h}$ work day and $40 \mathrm{~h}$ work week for the general public!

Proponents of long working hours for trainees seem to be rooted in the belief that shorter working hours may create a 'shift mentality' - a surrogate of less committed and incompetent doctors [1]. Asch et al. point out, it has become a shouting match with the proponents of shorter working hours calling long hours an exploitation of residents, which is akin to cheap, bonded labour. The irony is that though physician well-

Om Prakash Yadava

op_yadava@yahoo.com

1 National Heart Institute, 49-50, Community Centre, New Delhi 110065, India being, both physical and mental, have direct bearing on the patient's well-being, there is very limited amount of data available on the relation of the duty hours and the outcomes. A National Academy of Medicine report showed that sleep deprivation causes errors and that alertness and performance vary with the point in one's circadian rhythm [1]. However, there is no conclusive evidence that resident duty hours are associated with patient mortality or other clinical outcomes [2]. The FIRST Trial looking at 119 surgical residency programmes demonstrated non-inferiority of patient outcomes in surgical programmes using flexible duty hours [3].

It is time thus that we launch large-scale randomized controlled trials for various models available for surgical training rather than just base them on Class ' $\mathrm{C}$ ' recommendations of a few influential and elite senior colleagues sitting at the helm and who are totally out of synch with the current realities, expectations and aspirations of the trainee surgeons. Till such time, we wake up to these requirements of our present trainees, we will not be able to attract sufficient numbers and quality of talent that our speciality requires. We need to look at issues such as the length of the shift, number of work hours per week, flexible versus fixed hours, duration of our training programmes, the curricula, the hands-on training model versus simulation based training etc. Even our examination system, where only theoretical knowledge is tested, needs to be revisited. Physician burn-out, depression are other issues which merit serious and urgent attention of the authorities that be.

We need to wake up to these new realities and tailor our programmes to the needs and perception of our current trainees rather than using archaic models of training. It is with this intent that we have included a 'Young Surgeons Forum' in our journal, where we want to give unfettered and uncensored rights to our junior colleagues and trainees to voice their concerns and to initiate discussion points regarding issues concerning and bothering them and then take remedial 
measures to address them. Drs. Shetty and Arora, in an article 'Moving towards a competency-based training ideology' [4] this issue of the journal, voice their concern about the handson training curriculum, which produces a pittance of cardiac surgeon at the end of 6 years, not ready or equipped to take on the world. They make certain valid suggestions for, besides acquiring technical competence, developing the qualities of professionalism, teamwork, leadership and effective communication, so very integral to the making of a CTVS surgeon. These issues merit a serious thought by the administrators and the association as well as individual programme directors and mentors. Late, we are in debating these matters - but it is never too late, at least so they say.

Clarion call—wake up folks, before the horses bolt!

\section{References}

1. Asch DA, Bilimoria KY, Desai SV. Resident duty hours and medical education policy - raising the evidence bar. New Engl J Med. 2017;376:1704-6.

2. Philibert I, Nasca T, Brigham T, Shapiro J. Duty-hour limits and patient care and resident outcomes: can high-quality studies offer insights into complex relationships ? Annu Rev Med. 2013;64: 467-83.

3. Bilimoria KY, Chung JW, Hedges LV, et al. National cluster-randomized trial of duty-hour flexibility in surgical training. New Engl J Med. 2016;374:713-27.

4. Shetty V, Arora N. Moving towards a competency based training ideology. Ind J Thorac Cardiovasc Surg. 2017. doi:10.1007/ s12055-017-0569-z. 